\title{
Ex vivo conditioning with IL-12 decreases T cell sensitivity to intratumoral INF- $\gamma$-induced apoptosis following adoptive transfer
}

\author{
C Marcela Diaz-Montero ${ }^{*}$, Charles Tannenbaum, Patricia Rayman, Paul Pavicic, Jin Sub Kim, Marc Ernstoff, \\ James Finke
}

From 30th Annual Meeting and Associated Programs of the Society for Immunotherapy of Cancer (SITC 2015) National Harbor, MD, USA. 4-8 November 2015

\section{Background}

In order to induce significant tumor regression $\mathrm{T}$ cells must effectively recognize and kill target cells. Secretion of IFN- $\gamma$ is considered a key effector function of activated $\mathrm{CD} 8^{+} \mathrm{T}$ cells via induction of apoptosis. Thus programming $\mathrm{T}$ cells to secrete high levels of IFN- $\gamma$ after adoptive transfer could represent a therapeutically effective anti-cancer intervention.

\section{Methods}

We previously demonstrated that naïve $\mathrm{CD} 8^{+} \mathrm{T}$ cells exposed to IL-12 during antigenic priming ( $\mathrm{Pmel}^{\mathrm{Ag}+12}$ ) provided superior anti-tumor activity after transfer when compared to cells activated in the presence of antigen alone $\left(\mathrm{Pmel}^{\mathrm{Ag}}\right)$. In this setting, tumor regression was associated with sustained levels of intra-tumoral IFN- $\gamma$. Expression analysis using total tumor RNA showed elevated expression of IFN $-\gamma$ responsive genes such as IP-10, MCP-1, MIG, and MIP-1 $\alpha$. Even without IL-12 stimulation during ex vivo antigenic priming, Pmel cells were able to initially reach the tumor and secrete high levels of IFN- $\gamma$. However, by day 7 after adoptive transfer tumors in mice that received $\mathrm{Pmel}^{\mathrm{Ag}}$ were significantly larger than those in mice injected with $\mathrm{Pmel}^{\mathrm{Ag}+12}$. Failure to maintain intra-tumoral levels of IFN- $\gamma$ was associated with a decrease in the frequency of tumor infiltrating $\mathrm{Pmel}^{\mathrm{Ag}}$. We hypothesized that high levels of IFN- $\gamma$ had a detrimental effect on Pmel $^{\mathrm{Ag}}$, via induction of apoptosis. IFN- $\gamma$ is a multifunctional cytokine that induces a variety of contrasting cell responses such as proliferation or cell death. The cellular response to an IFN- $\gamma$ stimulus depends on the specific receptor being activated, with IFN- $\gamma \mathrm{R} 1$ inducing proliferation and IFN- $\gamma \mathrm{R} 2$ inducing apoptosis.

\section{Results}

We tested the hypothesis that the ability of $\mathrm{T}$ cells to survive in vivo after adoptive transfer was dependent on their susceptibility to IFN- $\gamma$-induced apoptosis. Real time PCR revealed that the expression levels of IFN- $\gamma$ R1 and IFN- $\gamma \mathrm{R} 2$ immediately following antigen or antigen+ IL-12 priming were similar, though by $4 \mathrm{~d}$ post adoptive transfer the tumor-infiltrating Pmel cells stimulated with antigen alone had 10 fold higher levels of IFN- $\gamma$ R2 than tumor associated $\mathrm{Pmel}^{\mathrm{Ag}+\mathrm{IL}-12}$.

\section{Conclusions}

These results suggest that the enhanced anti-tumor activity of Pmel ${ }^{\mathrm{Ag}+\mathrm{IL}-12}$ might be due to their decreased sensitivity to IFN- $\gamma$-induced apoptosis. Thus inhibiting IFN- $\gamma$-induced activation induced cell death (AICD) by down-regulating IFN- $\gamma \mathrm{R} 2$ expression on $\mathrm{T}$ cells may represent a novel mechanism by which IL-12 enhances anti-tumor activity.

Published: 4 November 2015

doi:10.1186/2051-1426-3-S2-P12

Cite this article as: Diaz-Montero et al:: Ex vivo conditioning with IL-12 decreases T cell sensitivity to intratumoral INF- $\gamma$-induced apoptosis following adoptive transfer. Journal for ImmunoTherapy of Cancer 2015 3(Suppl 2):P12. 